\title{
Erosão hídrica em um Argissolo Vermelho-Amarelo, sob diferentes padrões de chuva simulada ${ }^{1}$
}

\author{
João R. de Oliveira ${ }^{2}$, Marinaldo F. Pinto ${ }^{3}$, Wanderley de J. Souza ${ }^{4}$, José G. M. Guerra ${ }^{5}$ \& Daniel F. de Carvalho ${ }^{6}$
}

\begin{abstract}
RESUMO
Visou-se, neste trabalho, determinar as perdas de solo, água e nutrientes em um Argissolo Vermelho-Amarelo submetido a quatro diferentes padrões de chuva simulada. O estudo foi conduzido no Campo Experimental da Embrapa-Agrobiologia, localizado no município de Seropédica, RJ, e consistiu na aplicação de chuvas simuladas com diferentes padrões caracterizados como avançado (AV), intermediário (IN), atrasado (AT) e constante (CT), em uma área amostral de 0,80 m de largura por 1,0 m de comprimento. As chuvas tiveram duração de 60 min com uma lâmina total aplicada de $30 \mathrm{~mm}$ e um pico de $110 \mathrm{~mm} \mathrm{~h}^{-1}$, para os padrões de intensidade variável. Os resultados obtidos possibilitaram concluir que após 60 min de chuva simulada as perdas de solo e água observadas para o padrão atrasado foram, em média, superiores em 61,6, 46,4 e 13,6\%, respectivamente, para o CT, AV e IN (solo), e de 42,0, 19,0 e 19,0\%, respectivamente, para o AV, IN e CT (água) e as perdas de nutrientes não diferiram entre os padrões de precipitação, sendo mais influenciadas pelas perdas de água escoada superficialmente que pelo material sólido em suspensão.
\end{abstract}

Palavras-chave: perdas de solo, escoamento superficial, padrões de precipitação

\section{Water erosion in a Yellow-Red Ultisol under different patterns of simulated rain}

\begin{abstract}
This study was carried out in order to determine the soil, water and nutrient losses in a Yellow-Red Ultisol, under four different patterns of simulated rainfall. The experiment was conducted at the Embrapa Agrobiologia experimental field, located in the municipality of Seropédica, Rio de Janeiro, Brazil. The study consisted in the application of simulated rains using variable rainfall intensity classified in different patterns as: advanced (AD), intermediate (IN), delayed (DE), and constant $(\mathrm{CT})$, in plots $0.8 \mathrm{~m}$ wide and $1.0 \mathrm{~m}$ long. The rain had a duration of $60 \mathrm{~min}$, with a total applied depth of $30 \mathrm{~mm}$, and a peak of $110 \mathrm{~mm} \mathrm{~h}^{-1}$, for the variable intensity patterns. With the results obtained it was possible to verify that after 60 min of simulated DE pattern provided losses higher than $\mathrm{CT}, \mathrm{AD}$ and $\mathrm{IN}$, in $61.6,46.4$ and $13.6 \%$, respectively (soil), and 42.0, 19.0 and 19.0\% (run-off), respectively, for the AD, IN and CT patterns; and the nutrients losses did not differ among the rainfall patterns, being more affected by water run-off than solid material in suspension.
\end{abstract}

Key words: soil losses, run-off, precipitation patterns

\footnotetext{
1 Parte da Dissertação de Mestrado do primeiro autor, apresentada ao curso de Pós-graduação em Agronomia-Ciência do Solo/UFRRJ

2 INCRA/SR.14/AC, Rua Santa Inês, 135, Rio Branco, AC. E-mail: joao.oliveira@rbo.gov.incra.br

${ }_{3}^{3}$ Mestrando em Agronomia na ESALQ/USP. CEP 13418-900, Piracivaba, SP. Fone: (19) 3429-4217. E-mail: marinald@esalq.usp.br

${ }^{4}$ Doutorando em Agronomia ESALQ/USP. CEP 13418-900, Piracicaba, SP. Fone: (19) 3429-4217. E-mail: wjsouza@esalq.usp.br

${ }^{5}$ EMBRAPA/CNPAB. BR 465, km 7. CEP 23851-970, Seropédica, RJ. Fone: (21) 3441-1500. E-mail: gmguerra@cnpab.embrapa.br. Bolsista do CNPq.

${ }^{6}$ DE/UFRRJ. BR 465, km 7. CEP 23890-000, Seropédica, RJ. Fone: (21) 3787-3742. E-mail: carvalho@ufrrj.br. Bolsista do CNPq.
} 


\section{INTRODUÇÃO}

A deterioração dos solos é um dos principais problemas ambientais do planeta, sendo a erosão hídrica a forma mais prejudicial de degradação (Cogo et al., 2003). No mundo inteiro as taxas de erosão e consequente desgaste do solo vêm assumindo proporções espantosas, com enormes implicações de ordem física, financeira e social. No Brasil, a erosão hídrica é o principal fator capaz de tornar insustentáveis os sistemas de produção agrícola e os impactos ambientais dela oriundos têm reflexos no aumento dos custos causando, anualmente, um prejuízo econômico enorme ao País (Hernani et al., 2002). A cada ano são perdidos, em todo o território brasileiro, milhões de toneladas de solo agrícola devido à erosão; o que se nota principalmente na zona rural, é que as perdas por erosão continuam sendo elevadas, haja vista que a maioria dos agricultores ainda não utiliza técnicas de manejo nem de conservação adequadas ao solo.

A erosão hídrica é o resultado da interação do clima, solo, topografia, cobertura e manejo do solo e da adoção de práticas conservacionistas (Wischmeier \& Smith, 1958), e se manifesta de maneira variável sobre a superfície do terreno; as perdas de solo, água e nutrientes dela resultantes, são as principais responsáveis pelo empobrecimento das terras cultiváveis, o que leva a uma diminuição acelerada da capacidade produtiva pelo empobrecimento do solo e, consequentemente, insustentabilidade dos sistemas de produção agrícola (Bertol et al., 2004a). Esta influência negativa se torna ainda mais evidente nos terrenos que apresentam declividade acentuada e/ou desprovidos de cobertura vegetal. O desenvolvimento de modelos capazes de estimar as perdas ocasionadas por erosão hídrica é de fundamental importância para a escolha das práticas de conservação da água e do solo que possam tornar mínimos os impactos ambientais.

O regime pluvial e as características das chuvas ocorridas em uma região determinam, em grande parte, os efeitos danosos da erosão, sendo a intensidade de precipitação uma de suas principais características (Buckman \& Brady, 1976). As chuvas naturais apresentam consideráveis alterações em termos de intensidade durante sua ocorrência motivo pelo qual podem ser classificadas em diferentes padrões ou perfis de precipitação. Mehl (2000) classificou as chuvas em função do ponto de ocorrência do pico de maior intensidade de precipitação em padrões avançado, intermediário e atrasado. Segundo o autor, o padrão avançado é caracterizado quando a maior intensidade ocorre em um período de tempo menor do 30\% a partir do tempo inicial da chuva em relação ao seu tempo total de duração; padrão intermediário, quando a maior intensidade ocorre entre 30 e $60 \%$ do tempo total da chuva, e padrão atrasado, quando a maior intensidade se dá após mais de $60 \%$ do tempo total de duração e padrão constante quando a intensidade se mantém constante durante o tempo total de ocorrência. $\mathrm{O}$ autor verificou que as maiores perdas de solo e água ocorrem nos padrões intermediário e atrasado, devido à maior umidade da camada superficial do solo quando ocorre o pico de maior intensidade da chuva. Em solos mais úmidos a capacidade de infiltração tende a ser menor e a desagregação do solo pelo im- pacto das gotas da chuva também é favorecida, causando o selamento superficial e o escoamento superficial.

Assim, é de extrema importância avaliar a resposta dada pelas classes de solos aos diferentes tipos de precipitação, tanto em termos do volume precipitado quanto pela duração e característica dos eventos. Na atualidade, as pesquisas sobre precipitação no Brasil se têm restringido, na maioria das vezes, a estudos agroclimáticos (Keller Filho et al., 2005) ou com interesse em projetos e obras de engenharia de água e solo (Cardoso et al., 1998; Freitas et al., 2001). Poucos são os trabalhos sobre erosão hídrica que consideram as características das chuvas em perfil ou padrão de precipitação (variação da intensidade durante a sua ocorrência), o que pode influenciar as perdas de solo e água; também é notável que a maioria das pesquisas de erosão hídrica emprega modelos de precipitação estabelecidos para outros países (Oliveira, 2003), como também chuvas simuladas de intensidade constante, o que pode não retratar, de forma coerente, os processos erosivos e os padrões de chuvas naturais ocorridos nas diferentes regiões do País.

Tendo em vista a diversidade dos eventos de chuva de cada região e os impactos diferenciados que estes podem provocar, desenvolveu-se este trabalho com o objetivo de avaliar o efeito dos diferentes padrões de precipitação simulada nas perdas de solo, água e nutrientes, em um Argissolo Vermelho-Amarelo.

\section{MATERIAL E MÉTODOS}

Os trabalhos de campo foram conduzidos no Campo Experimental da Embrapa, denominada “Terraço", localizado no Centro Nacional de Pesquisa em Agrobiologia (Embrapa Agrobiologia), município de Seropédica, Estado do Rio de Janeiro, com coordenadas geográficas $22^{\circ} 46^{\prime}$ de latitude Sul e $43^{\circ} 41^{\prime}$ de longitude Oeste. O solo foi classificado como Argissolo Vermelho-Amarelo e as parcelas experimentais

Tabela 1. Características físicas e químicas do horizonte A do solo

\begin{tabular}{|c|c|c|}
\hline Características físicas e quimicas & Valor & Unidade \\
\hline \multicolumn{3}{|l|}{ Características físicas } \\
\hline Densidade de partículas & 2,67 & $\mathrm{~kg} \mathrm{dm}^{-3}$ \\
\hline Densidade do solo & 1,34 & $\mathrm{~kg} \mathrm{dm}^{-3}$ \\
\hline Diâmetro médio dos agregados & 3,52 & $\mathrm{~mm}$ \\
\hline Índice de estabilidade dos agregados $>0,25 \mathrm{~mm}$ & 92,48 & \\
\hline Areia $(0,05-2,0 \mathrm{~mm})$ & 580 & $\mathrm{~g} \mathrm{~kg}^{-1}$ \\
\hline Silte $(0,002-0,05$ mm) & 150 & $\mathrm{~g} \mathrm{~kg}^{-1}$ \\
\hline Argila total $(<0,002 \mathrm{~mm})$ & 260 & $\mathrm{~g} \mathrm{~kg}^{-1}$ \\
\hline Grau de floculação (\%) & 27 & \\
\hline \multicolumn{3}{|l|}{ Características químicas } \\
\hline $\mathrm{pH} \mathrm{H} \mathrm{H}_{2} \mathrm{O}$ & 4,9 & \\
\hline $\mathrm{Al}^{+++}$ & 0,20 & $\mathrm{cmol}_{\mathrm{c}} \mathrm{dm}^{-3}$ \\
\hline $\mathrm{Ca}^{++}$ & 2,8 & $\mathrm{cmol}_{\mathrm{c}} \mathrm{dm}^{-3}$ \\
\hline $\mathrm{Mg}^{++}$ & 1,3 & $\mathrm{cmol}_{\mathrm{c}} \mathrm{dm}^{-3}$ \\
\hline $\mathrm{P}^{++++}$ & 4,0 & $\mathrm{mg} \mathrm{dm} \mathrm{m}^{-3}$ \\
\hline $\mathrm{K}^{+}$ & 47,0 & $\mathrm{mg} \mathrm{dm}^{-3}$ \\
\hline M0 & 18,0 & $\%$ \\
\hline N & 1,1 & $\%$ \\
\hline
\end{tabular}


ocupavam o terço médio de uma encosta com declividade média de $0,09 \mathrm{~mm}^{-1}$. Na Tabela 1 se apresentam algumas características do horizonte superficial do solo da área experimental, referente ao horizonte A com profundidade de 0,16 m (Oliveira, 2007).

Três padrões de chuva, classificados como avançado (AV), intermediário (IN) e atrasado (AT) (Mehl, 2000) foram analisadas, além do padrão constante (CT), utilizado como comparação e largamente empregado no Brasil em estudos de erosão hídrica com chuva simulada. Adaptado de Eltz et al. (2001), um exemplo das chuvas nos padrões avançado, intermediário, atrasado e constante, está apresentado na Figura 1.

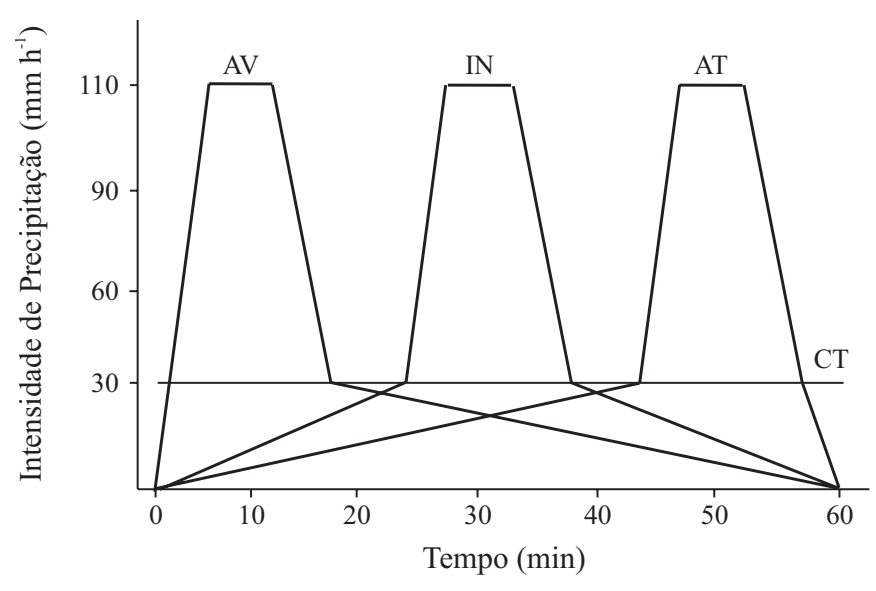

Figura 1. Padrões de precipitação avançado (AV), intermediário (IN), atrasado (AT) e constante (CT), utilizados nos experimentos

Adotaram-se, para os experimentos, chuvas com duração de 60 min e lâmina de precipitação de $30 \mathrm{~mm}$, que representa a lâmina média das chuvas intensas ocorridas na região de Seropédica, RJ (Carvalho et al., 2005). De acordo com a Figura 1, o pico de maior intensidade de precipitação (Ip) para os padrões AV, IN e AT, foi de $110 \mathrm{~mm} \mathrm{~h}^{-1}$, também determinado por Carvalho et al. (2005), com base no registro das chuvas intensas ocorridas na região de Seropédica, RJ.

Utilizou-se, para condução do experimento, um simulador de chuvas portátil semelhante ao descrito por Meyer \& Harmon (1979) e apresentado detalhadamente por Montebeller et al. (2001). Seguindo-se a recomendação desses autores, o simulador, equipado com bicos VeeJet $80-150$, foi regulado com uma pressão de $34,0 \mathrm{kPa}$, a fim de simular chuvas com características próximas às da chuva natural.

Com os dados de Ip, duração de aplicação da chuva, diâmetro médio das gotas aplicada pelo simulador, pressão de serviço do sistema e altura dos bicos aspersores, foi possível a determinação da energia cinética (Ec) para cada evento de chuva simulada utilizando o programa computacional "EnerChuva", desenvolvido por Alves Sobrinho et al. (2001). A partir desses resultados se obteve, também, o índice de erosividade $\left(\mathrm{EI}_{30}\right)$ para cada evento, conforme metodologia apresentada por Carvalho et al. (2005). De acordo com Foster et al. (1981), para cada seguimento de intensidade uniforme a energia cinética da chuva pode ser calculada pela Equação 1.

$$
\mathrm{E}=0,119+0,0873 \log \mathrm{I}
$$

em que:

$\mathrm{E}$ - energia cinética por mm de chuva, $\mathrm{MJ} \mathrm{ha}^{-1} \mathrm{~mm}^{-1}$ I - intensidade de chuva, $\mathrm{mm} \mathrm{h}^{-1}$

Os resultados obtidos pela Equação 1 foram, então, multiplicados pela lâmina de chuva precipitada em cada segmento e, em seguida, realizada a soma dos valores para um mesmo evento de chuva obtendo-se, assim, a energia cinética total (Ec) para cada chuva. $\mathrm{O} \mathrm{EI}_{30}$ foi calculado pelo produto da Ec pela máxima intensidade de chuva com duração de $30 \min \left(\mathrm{I}_{30}\right)$.

A área de experimentação se encontrava inativa há 20 anos e era ocupada por gramíneas, motivo pelo qual o preparo do terreno foi realizado, de início, com auxílio de um subsolador, seguido de um sistema de preparo convencional do solo (uma aração e duas gradagens). Este preparo foi realizado no sentido do declive do terreno, buscando-se simular condições críticas com relação à conservação do solo. Para se constatar a existência de variação das características físicas do solo realizou-se, antes de cada teste e ao lado de cada experimento, amostragem de solo em diferentes profundidades, visando à determinação do conteúdo de água, densidade do solo (método do anel volumétrico), macro e microporosidade (método da mesa de tensão) e porosidade total, de acordo com a metodologia preconizada por EMBRAPA (1997). Também, após o início do experimento, toda a área foi coberta com uma lona plástica com o objetivo de se manter a uniformidade das parcelas experimentais durante a realização dos testes, segundo recomendação de Mehl (2000).

Em virtude das variáveis físicas avaliadas não apresentarem diferenças estatísticas entre os locais em que seriam aplicados os tratamentos de chuva simulada, o experimento foi conduzido em delineamento inteiramente casualizado, com 4 tratamentos (padrões de precipitação AV, IN, AT e CT) e 5 repetições, totalizando 20 parcelas experimentais, delimitadas por chapas de aço com 0,25 m de altura e dimensões de $0,8 \mathrm{~m}$ por $1,0 \mathrm{~m}$ contendo, em um dos lados, um funil coletor para amostragem da enxurrada. As chapas foram cravadas no terreno com a maior dimensão no sentido do declive.

Antes da aplicação de cada chuva o solo foi pré-umedecido com o objetivo de se uniformizar as condições de umidade; para tal, o aparelho simulador foi instalado sobre a parcela em obediência às recomendações de Montebeller et al. (2001) e regulado, a fim de se aplicar uma chuva durante um tempo suficiente para umedecer o solo sem que houvesse escoamento superficial; após esta etapa, o equipamento foi desligado por aproximadamente $10 \mathrm{~min}$, a fim de permitir uma redistribuição de água no perfil e estabilização da umidade na camada superficial do solo.

Realizaram-se, para avaliação das perdas de solo, água e nutrientes, amostragens do escoamento superficial, em intervalos de 2 min ao longo do tempo de duração das chuvas simuladas, empregando-se, para tal, garrafas plásticas de $1 \mathrm{~L}$. Os instantes de amostragem do escoamento superficial foram definidos em função da variação da intensidade de precipitação presente em cada padrão, conforme Figura 1. No 
final de cada teste as amostras coletadas foram imediatamente agrupadas e encaminhadas ao laboratório, onde foram transferidas para recipientes de vidro, de massa conhecida e pesadas em balança de precisão; posteriormente, retirou-se uma pequena alíquota do material sobrenadante, proporcional ao volume escoado em cada recipiente e só então os mesmos, contendo as amostras, foram colocados em congelador até que a etapa de campo fosse concluída; a solução restante em cada recipiente foi levada à estufa de circulação forçada a $60{ }^{\circ} \mathrm{C}$, até massa constante, para a quantificação das perdas de solo e água.

Após o término do experimento em campo as amostras congeladas do sobrenadante foram analisadas no Laboratório de Solos do CNPAB (Embrapa Agrobiologia), possibilitando a determinação, por digestão nítrico-perclórica, dos conteúdos totais de $\mathrm{P}$, Ca, $\mathrm{Mg}$ e $\mathrm{K}\left(\mathrm{mg} \mathrm{L}^{-1}\right)$. Para a realização dessas análises $20 \mathrm{~mL}$ da suspensão foram pipetados para tubos de digestão e evaporados até $5 \mathrm{~mL}$ em blocos de digestão; a solução resultante sofreu ataque com uma mistura de $\mathrm{HNO}_{3}$ e $\mathrm{HClO}_{4}$, conforme preconizado por Tedesco et al. (1997). Nesse extrato se determinaram os teores de P e K total por fotometria de chama, e Ca e Mg total, por espectrofotometria de absorção atômica. O nitrogênio total em suspensão foi determinado em $20 \mathrm{~mL}$ de solução após a digestão sulfúrica (EMBRAPA, 1997). As perdas totais de nutrientes no escoamento superficial expressas em $\mathrm{g} \mathrm{m}^{-2}$, foram então calculadas mediante o produto das concentrações dos elementos em suspensão pelo volume de água escoada por unidade de área.

A estimativa da quantidade de solo e água presentes em cada amostra foi realizada determinando-se, inicialmente, a massa de sedimentos escoada por meio da pesagem direta de cada recipiente, após evaporação da água em estufa; obteve-se a massa de água subtraindo-se a massa de sólidos (g) presente após a evaporação em estufa da massa total de cada amostra (descontada a massa do recipiente de vidro). Realizaram-se, também, análises de nutrientes nos sedimentos através da mesma metodologia utilizada no material sobrenadante. As perdas totais de nutrientes nos sedimentos $\left(\mathrm{g} \mathrm{m}^{-2}\right.$ ) foram calculadas pelo produto das concentrações dos elementos nos sedimentos pela massa total perdida por unidade de área, enquanto os resultados foram avaliados pelas análises da variância e de comparação de médias, pelo teste Tukey a 5\%.

\section{RESULTADOS E DISCUSSÃO}

Mesmo com a variação da intensidade de precipitação durante o tempo de ocorrência das chuvas simuladas, a energia cinética acumulada não variou em comparação com o tratamento em intensidade constante (CT), sendo esta igual a $691,38 \mathrm{~J} \mathrm{~m}^{-2}$ ou $6,9138 \mathrm{MJ} \mathrm{ha}^{-1}$, para todos os padrões de precipitação (Tabela 2).

Os resultados apresentados na Tabela 2 evidenciam a qualidade da calibração do simulador de chuva na aplicação das diferentes intensidades de precipitação e também da correta distribuição dessas intensidades ao longo da duração da chu-
Tabela 2. Energia cinética (Ec, em $J \mathrm{~m}^{-2}$ ) das chuvas simuladas para os padrões de precipitação avançado (AV), intermediário (IN), atrasado (AT) e constante (CT), nos diferentes intervalos de tempo (IT, em min) ao longo da chuva

\begin{tabular}{|c|c|c|c|c|c|c|c|}
\hline \multicolumn{8}{|c|}{ Padrões de Precipitação } \\
\hline \multicolumn{2}{|c|}{ AV } & \multicolumn{2}{|c|}{ IN } & \multicolumn{2}{|c|}{ AT } & \multicolumn{2}{|c|}{ CT } \\
\hline IT & Ec & IT & Ec & IT & Ec & IT & Ec \\
\hline 2 & 7,68 & 10 & 38,41 & 18 & 69,14 & 60 & 691,38 \\
\hline 2 & 23,05 & 6 & 34,54 & 12 & 69,14 & & \\
\hline 2 & 46,09 & 4 & 30,73 & 8 & 61,46 & & \\
\hline 2 & 69,14 & 2 & 19,20 & 4 & 38,41 & & \\
\hline 4 & 169,00 & 2 & 23,05 & 2 & 23,05 & & \\
\hline 2 & 69,14 & 2 & 46,09 & 2 & 46,09 & & \\
\hline 2 & 46,09 & 2 & 69,14 & 2 & 69,14 & & \\
\hline 2 & 23,05 & 4 & 169,00 & 4 & 169,00 & & \\
\hline 4 & 38,41 & 2 & 69,14 & 2 & 69,14 & & \\
\hline 8 & 61,46 & 2 & 46,09 & 2 & 46,09 & & \\
\hline 12 & 69,14 & 2 & 23,05 & 2 & 23,05 & & \\
\hline \multirow[t]{4}{*}{18} & 69,14 & 2 & 19,20 & 2 & 7,68 & & \\
\hline & & 4 & 30,73 & & & & \\
\hline & & 6 & 34,54 & & & & \\
\hline & & 10 & 38,41 & & & & \\
\hline Total & 691,38 & - & 691,38 & - & 691,38 & - & 691,38 \\
\hline
\end{tabular}

va, caracterizando adequadamente cada padrão de precipitação estudado.

Apesar dos eventos de chuva obtidos com o simulador a partir dos diferentes padrões apresentarem a mesma energia cinética, seu índice de erosividade apresentou-se diferente com relação ao padrão constante. $\mathrm{O} \mathrm{EI}_{30}$ para os padrões avançado, intermediário e atrasado foi de 760,53 MJ mm ha-1 $\mathrm{h}^{-1}$, enquanto para o padrão constante foi de 207,41 $\mathrm{MJ} \mathrm{mm} \mathrm{ha}^{-1} \mathrm{~h}^{-1}$, cuja informação reforça a necessidade de se utilizar diferentes padrões de precipitação na simulação das perdas de solo e água, a fim de melhor representar as condições observadas nos eventos naturais.

A Figura 2 apresenta as taxas de perda de solo e água para os diferentes padrões de chuvas estudados. Na referida figura é possível observar que as taxas variaram conforme a variação da intensidade de precipitação, estando as maiores taxas associadas às maiores intensidades de precipitação para os padrões AV, IN e AT, conforme resultados obtidos por Hachum \& Alfaro (1977) e Eltz et al. (2001). As taxas máximas de perdas de solo foram, respectivamente, de 89; 61 e 23\% maiores na chuva do padrão atrasado em relação às chuvas simuladas com os padrões CT, AV e IN, enquanto as taxas máximas de perda de água foram, respectivamente, de 76, 47 e $17 \%$ maiores no padrão atrasado em relação aos mesmos padrões. Os valores máximos da taxa de perda de solo foram de aproximadamente 9,9, 33,7, 66,2 e 86,2 $\mathrm{g} \mathrm{m}^{-2} \mathrm{~h}^{-1}$, para os padrões CT, $\mathrm{AV}$, IN e AT, respectivamente, enquanto os valores máximos para a perda de água foram de 8,3, 18,4, 28,6 e $34,4 \mathrm{~mm} \mathrm{~h}^{-1}$, para os mesmos padrões.

O padrão CT apresentou taxas de perda de solo e água crescentes até determinado tempo após o início da chuva, atingindo o ponto máximo com tendência ao decréscimo; resultados similares são apresentados por Cassol \& Lima 

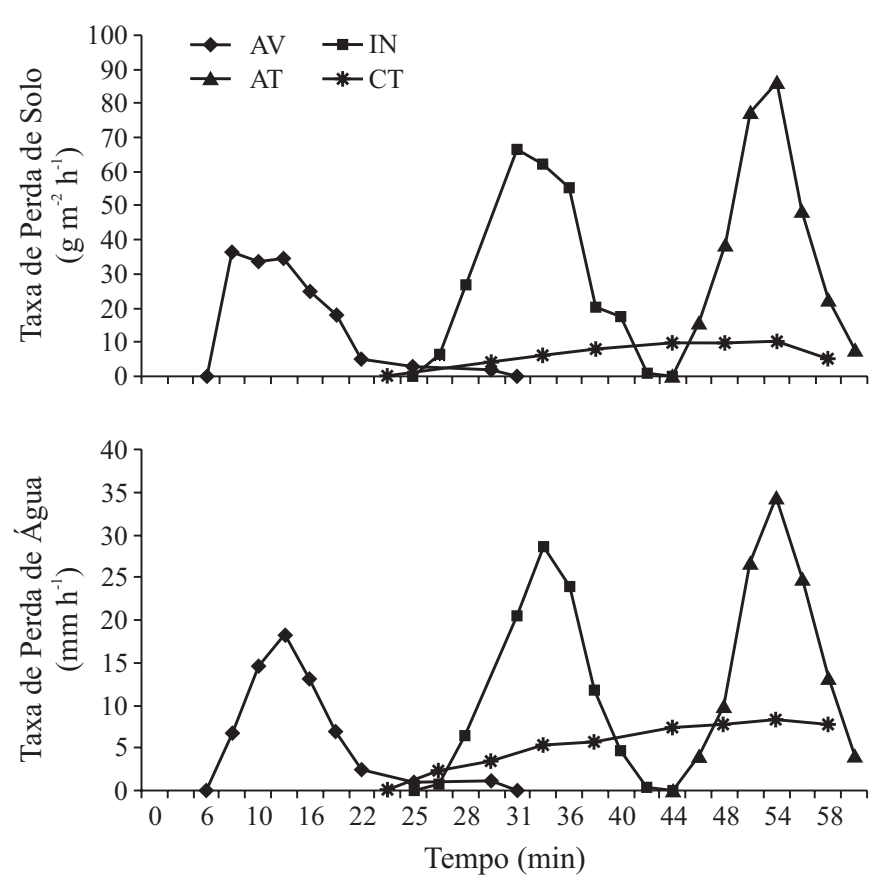

Figura 2. Taxas de perda de solo e água para os padrões de precipitação avançado (AV), intermediário (IN), atrasado (AT) e constante (CT)

(2003), ao aplicarem uma chuva simulada com intensidade constante de $60 \mathrm{~mm} \mathrm{~h}^{-1}$ durante $70 \mathrm{~min}$, em condição de solo descoberto.

Conforme a Figura 1, verifica-se que as maiores taxas de escoamento foram observadas ao se aplicarem altas intensidades ou quando a intensidade de precipitação se aproximou do seu valor máximo; este comportamento pode ser explicado pela própria dinâmica do teste haja vista que, quando a aplicação da chuva atinge intensidades superiores à taxa de infiltração do solo naquele instante, há um acúmulo de água na superfície e, consequentemente, escoamento superficial nesses pontos; por outro lado, quando a taxa de aplicação de água é baixa, o escoamento também é reduzido, podendo até nem ocorrer, quando a intensidade de precipitação for inferior à taxa de infiltração estável (TIE) de água no solo.

Coelho et al. (2000) comentam que, em condições de intensidade de precipitação abaixo da TIE, o microrrelevo superficial se comporta de maneira estável, apresentando uma superfície espelhada crescente (acúmulo de água) sobre o solo. Em condição de intensidade de precipitação acima da TIE, os autores notaram que a superfície espelhada se estabilizou mais rapidamente apresentando, posteriormente, a formação de canais preferenciais de escoamento de água sobre o solo (erosão laminar). Segundo Chow et al. (1988), a taxa de infiltração é um processo dinâmico, não dependente apenas da porosidade, permeabilidade de horizontes subsuperficial e umidade antecedente mas, também, de processos dinâmicos que ocorrem durante o fenômeno como selamento superficial gerado pela gota da chuva e redução do potencial mátrico do perfil causado pelo avanço da frente de molhamento.

A Figura 3 apresenta o comportamento das perdas acumuladas de solo e água em função do tempo da chuva simulada para os diferentes padrões de precipitação. As perdas totais de solo foram de 6,7, 10,8, 12,5 e 4,8 $\mathrm{g} \mathrm{m}^{-2}$, para os
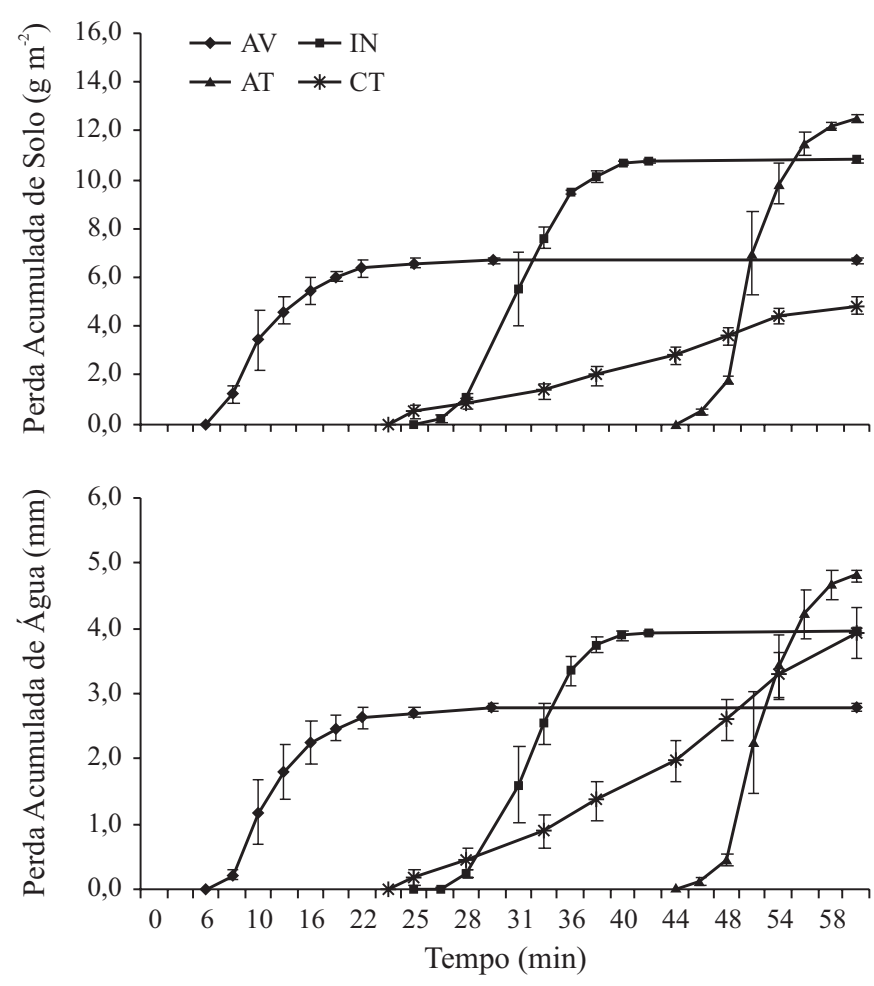

Figura 3. Perdas acumuladas de solo e água para os padrões de precipitação avançado (AV), intermediário (IN), atrasado (AT) e constante (CT)

padrões AV, IN, AT e CT, respectivamente, enquanto as perdas acumuladas de água foram de 2,8, 3,9, 4,8 e 3,9 mm, para os mesmos padrões.

Na Figura 3 é possível observar ainda que após a aplicação dos 60 min de chuva, o padrão AT provocou as maiores perdas acumuladas de solo e água, fato este ocorrido em virtude do momento da aplicação do pico de intensidade de precipitação. Conforme apresentado na Figura 1, neste padrão o pico de máxima intensidade, associado aos maiores valores de Ec, ocorre quando o solo já apresenta umidade elevada, favorecendo a formação de uma lâmina maior de escoamento superficial e, consequentemente, maior carreamento de sedimentos.

Verificou-se que o padrão de precipitação AT provocou perdas de solo superiores aos padrões CT, AV e IN em 61,6, 46,4 e 13,6\%, respectivamente; comportamento semelhante foi observado com as perdas de água, no qual o padrão AT apresentou uma lâmina de escoamento de 4,8 mm após $1 \mathrm{~h}$ de precipitação, mostrando ser superior aos padrões AV, IN e CT em cerca de 42,0, 19,0 e 19,0\%, respectivamente. As perdas de solo refletiram, de forma mais acentuada, as diferenças existentes entre os padrões de precipitação do que as perdas acumuladas de água, cujos resultados estão de acordo com Beutler et al. (2003), ao concluírem que as perdas de solo são mais afetadas pelo sistema de preparo e cultivo do que as perdas de água.

Os padrões de precipitação AV, IN e AT proporcionaram maiores valores de perda de solo e água que o padrão CT, em que os resultados corroboram com a hipótese de que o padrão de chuva CT, extensamente empregado em estudos de erosão hídrica no Brasil, não retrata, de forma coerente, 
os processos erosivos influenciados pelo padrão natural das chuvas. Eltz et al. (2001) concluíram que o padrão de precipitação AT foi o responsável pelas maiores perdas acumuladas e taxas máximas de perdas de água e solo, quando comparado com os padrões AV, IN e CT; neste estudo, os autores encontraram perdas de solo de 0,378, 0,464, 0,665 e 0,192 $\mathrm{kg} \mathrm{m}^{-2}$ e de água na ordem 15,5, 13,9, 16,9 e 7,5 mm para os padrões AV, IN, AT e CT, respectivamente. As perdas encontradas por Eltz et al. (2001) são expressivamente superiores às encontradas neste estudo, porém se ressalta que as condições de pesquisa foram distintas, a começar pela lâmina de precipitação empregada (35 mm), pico de intensidade de precipitação (120 $\mathrm{mm} \mathrm{h}^{-1}$ ) e declividade da rampa na área estudada $\left(0,12 \mathrm{~m} \mathrm{~m}^{-1}\right)$, além do menor conteúdo de argila na camada superficial do solo estudado, facilitando a desagregação do mesmo; por sua vez, os autores não apresentaram os valores de energia cinética da chuva, simulada por um simulador estacionário de bicos múltiplos e oscilantes.

Carvalho et al. (2002) constataram, estudando as perdas de solo e água em um Argissolo apenas roçado, que uma chuva com intensidade de precipitação constante de $30 \mathrm{~mm} \mathrm{~h}^{-1}$ e energia cinética igual a $138 \mathrm{~J} \mathrm{~m}^{-2}$, após $35 \mathrm{~min}$, provocou perdas de solo e água na ordem de 2,86 $\mathrm{g} \mathrm{m}^{-2} \mathrm{e}$ 2,21 mm, respectivamente, estando esses resultados em concordância com os obtidos neste trabalho.

Aplicando uma chuva com duração de 35 min e intensidade de precipitação de $55 \mathrm{~mm} \mathrm{~h}^{-1}$ em um Argissolo sob diferentes condições de cobertura e preparo, Carvalho et al. (2002) verificaram perdas de solo e água em torno de $41,0 \mathrm{~g} \mathrm{~m}^{-2}$ e 9,49 mm, respectivamente, para o solo arado e gradeado desprovido de cobertura morta; da mesma forma, Silva et al. (2005) estudando atributos físicos, químicos e erosão hídrica em um Latossolo submetido a uma chuva constante de $60 \mathrm{~mm} \mathrm{~h}^{-1}$, notaram perdas de solo da ordem de 7,5 e 1,96 $\mathrm{g} \mathrm{m}^{-2}$ e de água da ordem de 5,45 e 6,62 mm, respectivamente, para os sistemas de sucessão milho-pousio em preparo convencional do solo e sucessão milho-pousio em plantio direto.

Apesar das diferenças observadas nas taxas (Figura 2) e nas perdas acumuladas (Figura 3), não se obtiveram, pela análise estatística, diferenças significativas dessas variáveis entre os diferentes padrões de precipitação; no entanto, a utilização de chuvas simuladas com padrões AV, IN e AT sugere a obtenção de perdas mais acentuadas quando comparadas com o padrão constante. Carvalho et al. (2009), trabalhando em parcelas de perda de solo com dimensão de 3,5 x 22,0 m, instaladas ao lado da área experimental, verificaram que as chuvas naturais classificadas com padrão atrasado, em comparação aos padrões avançado e intermediário, foram responsáveis pelas maiores perdas de solo e água, após o período de chuva analisado. A partir dos resultados obtidos os autores definiram um índice que representa a energia necessária para causar o escoamento superficial de $1 \mathrm{~mm}$ de lâmina. Os resultados encontrados foram de 11,2, 6,9 e 1,6 MJ mm ha-1 $\mathrm{h}^{-1} \mathrm{~mm}^{-1}$, para os padrões AV, IN e AT, respectivamente, indicando ser o padrão atrasado (AT) aquele que necessita da menor energia cinética da chuva para produzir a mesma lâmina de escoamento superficial.

Apresentam-se, na Tabela 3, as perdas de nutrientes ob- servadas quando foram aplicadas as chuvas simuladas com os diferentes padrões de precipitação; da mesma forma que o observado para as perdas de solo e água, as perdas de nutrientes na água e nos sedimentos da enxurrada não foram diferentes significativamente entre os tratamentos.

Tabela 3. Perda de nutrientes $\left(10^{4} \mathrm{~g} \mathrm{~m}^{-2}\right)$ na água e nos sedimentos da enxurrada para quatro padrões de precipitação

\begin{tabular}{lccccc}
\hline $\begin{array}{l}\text { Padrões de } \\
\text { Precipitação }\end{array}$ & $\mathbf{C a}$ & $\mathbf{M g}$ & $\mathbf{K}$ & $\mathbf{N}$ & $\mathbf{P}$ \\
\multicolumn{7}{c}{ Perda de nutrientes em suspensão } \\
Avançado & $262,5 \mathrm{~A}$ & $107,9 \mathrm{~A}$ & $140,5 \mathrm{~A}$ & $118,9 \mathrm{~A}$ & $*$ \\
Intermediário & $490,9 \mathrm{~A}$ & $155,3 \mathrm{~A}$ & $271,2 \mathrm{~A}$ & $138,7 \mathrm{~A}$ & $*$ \\
Atrasado & $450,5 \mathrm{~A}$ & $154,6 \mathrm{~A}$ & $257,7 \mathrm{~A}$ & $190,9 \mathrm{~A}$ & $*$ \\
Constante & $416,1 \mathrm{~A}$ & $130,8 \mathrm{~A}$ & $394,8 \mathrm{~A}$ & $172,0 \mathrm{~A}$ & $*$ \\
\multicolumn{7}{c}{ Perda de nutrientes adsorvidos aos sedimentos } \\
Avançado & $3,2 \mathrm{~A}$ & $2,2 \mathrm{~A}$ & $2,2 \mathrm{~A}$ & $* *$ & $0,4 \mathrm{~A}$ \\
Intermediário & $2,9 \mathrm{~A}$ & $1,8 \mathrm{~A}$ & $2,7 \mathrm{~A}$ & $* *$ & $0,4 \mathrm{~A}$ \\
Atrasado & $6,2 \mathrm{~A}$ & $1,5 \mathrm{~A}$ & $2,3 \mathrm{~A}$ & $* *$ & $0,4 \mathrm{~A}$ \\
Constante & $2,8 \mathrm{~A}$ & $1,0 \mathrm{~A}$ & $1,0 \mathrm{~A}$ & $* *$ & $0,1 \mathrm{~A}$ \\
\hline
\end{tabular}

Médias seguidas de mesma letra na coluna, não diferem entre si por Tukey a $5 \%$ de significância * Elemento não detectado pela metodologia empregada; ** Elemento não determinado devido à falta de material para análise

Nota-se que as maiores perdas de nutrientes ocorreram em suspensão, conforme resultados obtidos por Bertol et al. (2005). Este comportamento é explicado em virtude da perda de água ter ocorrido em magnitudes bem superiores às perdas de solo. Os autores Bertol et al. (2005) concluíram que as concentrações de $\mathrm{Ca}$ e $\mathrm{Mg}$ foram maiores nos sedimentos que na água da enxurrada superficial, enquanto as perdas totais desses elementos foram maiores na água que nos sedimentos.

No escoamento superficial não se registraram perdas de fósforo, provavelmente por ter ocorrido em concentrações inferiores à sensibilidade do aparelho, o que condicionou concentração insuficiente para que a mesma fosse detectada pela metodologia empregada, resultado que também se justifica em virtude dos baixos valores deste elemento no solo, conforme a Tabela 1. Segundo Schick et al. (2000), em razão do elemento estar adsorvido aos colóides do solo, o maior transporte ocorre nas frações de argila e silte, implicando em maiores perdas nos sedimentos da enxurrada. Nuñes et al. (2003), comentam que a forma inorgânica do fósforo nos solos pode chegar a $90 \%$ e o elemento pode ser perdido por erosão, tanto na forma solúvel como na oclusa; como o elemento é fortemente adsorvido pelas argilas (Sposito, 1989), uma proporção maior é transportada na forma adsorvida, juntamente com as partículas do solo, fato que pode explicar a não ocorrência do elemento em suspensão na água da enxurrada, influenciando na sua ausência na fração líquida. Salienta-se que, em função da pequena quantidade de solo, não se realizaram as análises de nitrogênio nos sedimentos.

As perdas de nutrientes nos sedimentos foram relativamente baixas quando comparadas com as perdas no escoamento superficial; as baixas quantidades perdidas nos sedimentos foram influenciadas, sobretudo, pelas baixas perdas de solo provocadas pelos tratamentos de chuva, concordando com os resultados apresentados por Bertol et al. (2004b). 
As maiores perdas de potássio foram registradas na água escoada superficialmente, conforme resultados encontrados por Hernani et al. (1999). Os autores afirmaram que, normalmente, as perdas de potássio em suspensão são maiores que as encontradas no sedimento em função da maior solubilidade deste elemento; da mesma forma, as perdas de Ca e $\mathrm{Mg}$ foram diretamente influenciadas pelas perdas de água.

Apesar dos resultados obtidos neste trabalho não terem apresentado diferenças significativas, estudos com simuladores de chuva que possibilitam a aplicação de eventos com diferentes padrões, devem ser intensificados, a fim de permitirem conhecer o efeito desses eventos em diferentes condições de solo e cobertura.

\section{CONCLUSÕES}

1. Após 60 min de precipitação simulada as perdas de solo e água observadas para o padrão atrasado foram superiores, em ordem decrescente, para o CT, AV e IN (solo) e para o $\mathrm{AV}$, IN e CT (água), respectivamente;

2. As perdas de nutrientes foram pouco afetadas pelos padrões de precipitação, sendo mais influenciadas pela água da enxurrada que pelo material sólido em suspensão.

\section{LITERATURA CITADA}

Alves Sobrinho, T.; Carvalho, D. F.; Aquino, R. M. de; Montebeller, C. A. Programa computacional para a definição de parâmetros hidráulicos utilizados na determinação da energia cinética da chuva simulada em infiltrômetros de aspersão. Engenharia Rural, v.12, p.15-19, 2001.

Bertol, I.; Guadagnin, J. C.; Casol, P. C.; Amaral, A. J.; Barbosa, F. T. Perdas de fósforo e potássio por erosão hídrica em um Inceptisol sob chuva natural. Revista Brasileira de Ciência do Solo, v.28, n.3, p.485-494, 2004a.

Bertol, I; Guadagnin, J. C.; González, A. P.; Amaral, A. J. do; Brignoni, L. F. Soil tillage, water erosion, and calcium, magnesium and organic carbon losses. Scientia Agricola, v.62, n.6, p.578-584, 2005.

Bertol, I.; Leite, D.; Guadagnin, J. C.; Ritter, S. R. Erosão hídrica em um Nitosolo Háplico submetido a diferentes sistemas de manejo sob chuva simulada. II - Perdas de nutrientes e carbono orgânico. Revista Brasileira de Ciência do Solo, v.28, n.5, p.1045-1054, 2004b.

Beutler, J. F.; Bertol, I.; Veiga, M.; Wildner, L. P. Perdas de solo e água num Latossolo Vermelho aluminoférrico submetido a diferentes sistemas de preparo e cultivo sob chuva natural. Revista Brasileira de Ciência do Solo, v.27, p.509-517, 2003.

Buckman, H. O.; Brady, N. C. Natureza e propriedades dos solos. 4.ed. Rio de Janeiro: Freitas Bastos, 1976. 595p.

Cardoso, C. O.; Ullmann, M. N.; Bertol, I. Análise das chuvas intensas a partir da desagregação das chuvas diárias de Lages e de Campos Novos (SC). Revista Brasileira de Ciência do Solo, v.22, p.131-140, 1998.
Carvalho, D. F.; Cruz, E. S.; Pinto, M. F.; Silva, L. D. B.; Guerra, J. G. M. Características da chuva e perdas por erosão sob diferentes práticas de manejo do solo. Revista Brasileira de Engenharia Agrícola e Ambiental, v.13, n.1, p.3-9, 2009.

Carvalho, D. F.; Montebeller, C. A.; Cruz, E. S.; Ceddia M. B.; Lana, A. M. Q. Perdas de solo e água em um Argissolo Vermelho Amarelo, submetidos a diferentes intensidade de chuva simulada. Revista Brasileira de Engenharia Agrícola e Ambiental, v.6, n.3, p.385-389, 2002.

Carvalho, D. F.; Montebeller, C. A.; Franco, E. M.; Valcarcel, R.; Bertol, I. Padrões de precipitação e índices de erosividade para as chuvas de Seropédica e Nova Friburgo-RJ. Revista Brasileira de Engenharia Agrícola e Ambiental, v.9, n.1, p.7-14, 2005.

Cassol, A. E.; Lima, V. S. de. Erosão em entressucos sob diferentes tipos de preparo e manejo do solo. Pesquisa Agropecuária Brasileira, v.38, n.1, p.117-124, 2003.

Chow, V. T.; Maidment, D. R.; Mays, Y. W. Applied hydrology. New York: McGraw-Hill, 1988. 572p.

Coelho, R. D.; Miranda, J. H. de; Duarte, S. N. Infiltração da água no solo: Parte II acúmulo de água sobre a superfície do terreno. Revista Brasileira de Engenharia Agrícola e Ambiental, v.4, n.2, p.142-145, 2000.

Cogo, N. P.; Levien, R.; Schwarz, R. A. Perdas de solo e água por erosão hídrica influenciadas por métodos de preparo, classes de declive e níveis de fertilidade do solo. Revista Brasileira de Ciência do Solo, v.27, p.743-753, 2003.

Eltz, F. L. F.; Mehl, H. U.; Reichert, J. M. Perdas de solo e água em entressulcos em um Argissolo Vermelho-Amarelo submetido a quatro padrões de chuva. Revista Brasileira de Ciência do Solo, v.25, p.485-493, 2001.

EMBRAPA - Empresa Brasileira de Pesquisa Agropecuária. Manual de métodos de análise do solo. 2.ed. Rio de Janeiro: Embrapa CNPS, 1997. 212p.

Foster, G. R.; McCool, D. K.; Renard, K. G.; Moldenhaeur, W. C. Conversion of the Universal Soil Loss Equation to SI units. Journal of Soil and Water Conservation, v.36 p.335-359.1981.

Freitas, A. J.; Silva, D. D.; Pruski, F. F.; Pinto, F. A.; Pereira, S. B.; Gomes Filho, R. R.; Texeira, A. F.; Baena, L. G. N.; Mello, L. T. A.; Novais, L. F. Equações de chuva intensas no Estado de Minas Gerais. Belo Horizonte: Companhia de Saneamento de Minas Gerais, 2001. 65p.

Hachum, A. Y.; Alfaro, J. F. Water infiltration and runoff under rain applications. Soil Science Society of America Journal, v.41, p.960-966. 1977.

Hernani, L. C.; Freitas, P. L.; Pruski, F. F.; Maria, I. C. de; Castro Filho, C.; Landers, J. C. A erosão e seu impacto. p.47-60. In: Manzatto, C. V.; Freitas Júnior, E.; Peres, J. R. R. (ed.) Uso agrícola dos solos brasileiros. Rio de Janeiro: EMBRAPA, 2002. 174p..

Hernani, L. C.; Kurihara, C. H.; Silva, W. M. Sistemas de manejo de solo e perdas de nutrientes e matéria orgânica por erosão. Revista Brasileira de Ciência do Solo. v.23, p.145-154. 1999.

Keller Filho, T.; Assad, E. D.; Lima, P. R. S. R. Regiões pluviometricamente homogêneas no Brasil. Pesquisa Agropecuária Brasileira, v.40, n.4, p.311-322, 2005.

Mehl, H. U. Caracterização de padrões de chuvas ocorrentes em Santa Maria (RS) e sua relação com as perdas de solo e água em entre sulcos. Santa Maria: UFSM, 2000. 53p. Dissertação Mestrado 
Meyer, L. D.; Harmon, W. C. Multiple intensity rainfall simulator for erosion research on row sideslopes. Transactions of the ASAE, v.22, n.1, p.100-103, 1979.

Montebeller, C. A.; Carvalho, D. F.; Alves Sobrinho, T.; Nunes, A. C. S.; Rubio, E. Avaliação hidráulica de um simulador de chuva pendular. Revista Brasileira de Engenharia Agrícola e Ambiental, v.5, n.1, p.1-5, 2001.

Nuñez, J. E. V.; Amaral Sobrinho, N. M. B.; Mazur, N. Conseqüência de diferentes sistemas de preparo do solo sobre distribuição química e perdas de fósforo de um Argissolo. Bragantia, v.62, n.1, p.101-109, 2003.

Oliveira, J. R. de. Perdas de solo, água e nutrientes em um Argissolo Vermelho-Amarelo sob diferentes padrões de chuva simulada. Seropédica: UFRRJ, 2007. 52p. Dissertação Mestrado

Oliveira, V. P. S. Modelo para geração de séries sintéticas de precipitação. Viçosa: UFV, 2003. 156p. Tese Doutorado
Schick, J.; Bertol, I.; Batistela, O.; Balbinot Júnior, A. A. Erosão hídrica em Cambissolo Húmico Alumínico submetido a diferentes sistemas de preparo e cultivo do solo: I. Perdas de solo e água. Revista Brasileira de Ciência do Solo, v.24, p.427-436, 2000.

Silva, C. G.; Alves Sobrinho, T.; Vitorino, A. C. T.; Carvalho, D. F. Atributos físicos, químicos e erosão hídrica entressulcos sob chuva simulada, em sistema de plantio direto e convencional. Engenharia Agrícola, v.25, n.1, p.144-153, 2005.

Sposito, G. The chemistry of soils. New York: Oxford University Press, 1989. 234p.

Tedesco, M. J.; Gianello, C.; Bissani, C. A.; Bohnen, H.; Volkweiss, S. J. Análise de solo, plantas e outros materiais. 2.ed. Porto Alegre: UFRGS, 1997. 174p.

Wischmeier, W. H.; Smith, D. D. Rainfall energy and its relationship to soil loss. Transactions of the American Geophysical Union, v.39, p.285-291, 1958. 